\title{
DE AFZETTING VAN LUMUMBA DOOR KASAVUBU, ENKELE GRONDWETTELIJKE BESCHOUWINGEN
}

\author{
Dirk BEKE
}

\section{SUMMARY}

\section{THE DEPOSITION OF LUMUMBA BY KASAVUBU, SOME CONSTITUTIONAL CONSIDERATIONS}

Shortly after the independence of the Congo, the political crisis engendered by the conflict between President Kasavubu and Prime Minister Lumumba was accompanied by a serious constitutional crisis. The first Congolese constitution was almost a complete imitation of the Belgian constitution. It established a parliamentary regime with a politically accountable Prime Minister and a non-accountable President as Head of State. The confusing rubric that 'The Head of State appoints and dismisses the Prime Minister' was quickly misused by national and international opponents of Lumumba to persuade Kasavubu to remove him from power. A full and contextual analysis of the constitution, however, shows that dismissal is linked to several other formal procedures and political conditions. Every presidential decision, including the dismissal of the Prime Minister and of Ministers, has to be countersigned by a Minister. Furthermore, it can be deduced clearly from the whole constitutional model that dismissal of the Prime Minister can only take place when the government has been outvoted in parliament. The conclusion is that, in contradiction to the.. contrived interpretations of some advisers and Belgian jurists, the deposition of Lumumba was unconstitutional. At any rate, Kasavubu's unconstitutional act seriously 
damaged Lumumba's political position and placed him in a difficult situation of legal defence against it.

KEY WORDS : Congo, Constitution, Lumumba, Politics

\section{Inleiding}

De politieke crisis, kort na de onafhankelijkheid van Congo, tussen de president en de eerste minister, met name tussen Kasavubu en Lumumba, ging gepaard met een constitutionele crisis. Door beide partijen werden diametraal tegengestelde interpretaties van de grondwet naar voor geschoven zodat de grondwet zelf een element is geworden in de politieke strijd. De problematiek toont duidelijk aan dat door Congolese politici en hun raadgevers, door Belgische politici en door $\mathrm{VN}$-verantwoordelijken gretig gebruik gemaakt is om de juridische interpretaties naar hun hand te zetten in een poging om hun respectievelijke politieke doelstellingen te ondersteunen.

Deze korte bijdrage wil met een analyse van de grondwettelijke bepalingen in hun onderlinge samenhang en in de context van het gehele grondwettelijke bestel, nagaan of het ontslag van Lumumba door Kasavubu al of niet grondwettig was. Het onderzoek wil zich richten op dit eerste politieke manoeuvre. De constitutionele aspecten van de reacties hierop, meer bepaald de afzetting van Kasavubu door Lumumba en kort daarop de eerste staatsgreep van Mobutu met de installatie van een College van Commissarissen, zullen in een latere bijdrage bekeken worden. ${ }^{1}$

\footnotetext{
${ }^{1}$ Chronologisch zijn de gebeurtenissen als volgt samen te vatten: Op 5 september 1960 ontslaat President Kasavubu eerste minister Lumumba en zes ministers omwille van zogenaamde 'arbitraire' uitoefening van hun taak die oorzaak zou zijn van de burgeroorlog. Lumumba reageert nog dezelfde dag met de mededeling dat deze daad ongrondwettig is en dat daarom Kasavubu geen president meer kan zijn. Op 7 en 8 september verwerpt het parlement de wederzijdse afzettingen. Lumumba verklaart op 9 september zowel de taak van eerste minister als voorlopig deze van president waar te nemen. Kasavubu benoemt op 12 september de tegenregering Ileo en laat Lumumba arresteren. Op 13 september besluiten de Verenigde Kamers, onder dubieuze omstandigheden, op vraag van Lumumba hem alle machten toe te kennen. Stafchef Mobutu 'neutraliseert' op 14 september zowel Kasavubu als Lumumba; nadien is gebleken dat deze actie vooral gericht was tegen Lumumba. Op 20 september wordt onder druk van Mobutu en met de instemming van Kasavubu een 'College van Commissarissen' als nieuwe regering geïnstalleerd.
} 


\section{De bepalingen in de Fundamentele Wet}

De formulering over de benoeming en het ontslag van de eerste minister in de eerste grondwet van Congo, de 'Fundamentele Wet betreffende het staatsbestel van Congo', lijkt op het eerste zicht klaar en duidelijk, artikel 22 stelt immers kort en bondig: "Het Staatshoofd benoemt en ontslaa( $g) t$ de Eerste-Minister en de Ministers."

Dit artikel is misleidend omdat in andere artikels van de grondwet essentiële beperkingen worden geformuleerd met betrekking tot de uitoefening van deze bevoegdheden door de president. Iemand die zich beperkt tot het lezen van artikel 22 zou snel kunnen besluiten dat de president eigenmachtig de eerste minister kan ontslaan. Een eerste probleem is dat wanneer deze simpele formulering op tafel wordt geworpen, de tegenpartij alvast in de verdediging moet gaan. Hij wordt verplicht om door verwijzing naar de andere artikels en naar de grondwettelijke rechtsleer aan te tonen dat de Congolese president bij deze beslissingen gebonden is aan strikte grondwettelijke procedures.

Een eerste indruk bij het geïsoleerd lezen van artikel 22 kan zijn dat het Congolese staatsbestel zou aansluiten bij een presidentieel regime. De ontleding van de eerste Congolese grondwet toont evenwel duidelijk dat dit regime ver af stond van een presidentieel stelsel. De Fundamentele Wet is op veel punten bijna een kopie van de Belgische grondwet met een parlementair stelsel. Het staatshoofd is wel geen erfelijke constitutionele monarch maar een president, die wordt benoemd "bij meerderheid van twee derden van alle leden van beide verenigde Kamers"' In deze republikeinse staatsvorm is het staatshoofd, zoals in België, politiek 'onverantwoordelijk'. De politieke verantwoordelijkheid valt op de eerste minister en de ministers. ${ }^{4}$ De grondwet bepaalt verder uitdrukkelijk dat iedere beslissing van het staatshoofd moet medeondertekend worden door een minister die hiervoor de politieke verantwoordelijkheid opneemt. ${ }^{5}$ Verder wordt in de grondwet ook gesteld: "Het Staathoofd heeft geen andere macht dan die welke deze wet hem uitdrukkelijk toekent ..." bovendien moeten deze machten, inclusief de benoeming en het ontslaan van de ministers, uitgeoefend worden onder bepaalde voorwaarden zoals

\footnotetext{
2 Fundamentele wet betreffende het staatsbestel van Congo, 16 mei 1960. Belgisch Staatsblad, 27-28 mei 1960, p. 3988.

${ }^{3}$ Artikel 12.

4 "Art. 19. De persoon van het Staatshoofd is onschendbaar; de Eerste-Minister en de Ministers zijn verantwoordelijk"

${ }^{5}$ Artikel 20.
} 
de medeondertekening door de verantwoordelijke minister. ${ }^{6}$ De essentie van de medeondertekening wordt benadrukt doordat hieraan uitdrukkelijk is toegevoegd "In geen geval kan een mondeling of schriftelijk bevel van het Staatshoofd een Minister van zijn verantwoordelijkheid ontheffen."7

Op dit vlak is Kasavubu voorzichtig geweest. Onmiddellijk na zijn beslissing tot afzetting van Lumumba vaardigt hij een presidentiële verordening uit die is medeondertekend door twee ministers, Delvaux en Bomboko. ${ }^{8}$

In de grondwet staat evenwel nog meer dan de vereiste van medeondertekening. Artikel 36 toont duidelijk dat de rol van de eerste minister essentieel blijft. Het artikel bepaalt dat de eerste minister de leiding heeft over de staatspolitiek in overleg met de ministerraad. De eerste minister - en niet de president, zoals in presidentiële regimes - zit deze ministerraad voor. Bovendien moeten, volgens dit artikel, de voorstellen aan het staatshoofd betreffende de uitoefening van de verordende bevoegdheid door de eerste minister voorgelegd worden. ${ }^{9}$

\section{De theorie van de hulpeloze staat}

Dit formele aspect van de medeondertekening is voor velen blijkbaar het doorslaggevend argument geworden om te stellen dat het ontslag van Lumumba grondwettig zou geweest zijn. Onder meer de jurist J.M. Moreels, de Belgische 'Voorlopig Secretaris-generaal van de Congolese Kamer van Afgevaardigden' kort voor en kort na de onafhankelijkheid, ontwikkelt uitvoerig de stelling dat de afzetting conform zou zijn met de Fundamentele Wet.

\footnotetext{
${ }^{6}$ Artikel 21.

${ }^{7}$ Artikel 20, tweede lid.

${ }^{8}$ Ordonnance du 5 septembre 1960 révoquant le Premier Ministre et certains ministres. Moniteur Congolais, $\mathrm{n}^{\circ}$ 40, 3 octobre 1960.

9 “Art. 36. De Eerste-Minister heeft de leiding van de Staatspolitiek in gemeen overleg met de Ministerraad die hij voorzit.

Hij heeft de leiding van het regeringsbeleid.

Hij legt aan het Staatshoofd de voorstellen over betreffende de uitoefening van de verordende bevoegdheid en de uitvoering van de wetten."
} 
Voor J.M. Moreels was de afzetting - in tegenstelling tot wat Van Bilsen stelde $^{10}$ - bovendien ook politiek volkomen verantwoord. De overigens erg interessante en goed gedocumenteerde bijdrage van J.M. Moreels, geschreven in oktober 1960, is gepubliceerd in het bekende Belgische 'Tijdschrift voor Bestuurswetenschappen en Publiek Recht' en zal zo ongetwijfeld invloed gehad hebben op de opinie in België. ${ }^{11}$

De uitvoerige argumentatie die J.M. Moreels opbouwt is erg relevant voor de nauwe verwevenheid tussen juridische interpretatie en politieke opinie. Het valt ook op hoe dicht de stellingen van J.M. Moreels aansluiten bij de toen gangbare Belgische kolonialistisch paternalistische visie. ${ }^{12}$ Moreels toont zich hierbij - in tegenstelling tot Van Bilsen - een van de vele aanhangers van de visie dat de moeilijkheden voor de werking van de Congolese instellingen de voornaamste oorzaak zouden vinden in de onverenigbaarheid van deze instellingen met de 'bantu cultuur'. Onder meer Jan Blommaert weerlegt terecht deze stelling, die in heel wat invloedrijke werken over de Congo crisis opduikt. ${ }^{13}$

Kort samengevat is de argumentatie van J.M. Moreels: "In onze meer ontwikkelde parlementaire democratieën is de afzetting van een minister door het staatshoofd een zeldzaamheid." 14 In "hulpeloze staten als de republiek Kongo" is dit anders; daar is geen twijfel dat een bepaling die formeel stelt dat het staatshoofd de eerste minister en de ministers benoemt en ontslaat, inhoudt dat de president een eerste minister zou kunnen afzetten (zonder eerst een wantrouwenmotie van het parlement) wanneer hij oordeelt dat dit nodig is voor de werking van de staatsinstellingen. J.M. Moreels besluit dan ook: "De hr. Kasavubu blijkt deze stelregel te hebben nageleefd. Hij heeft de h. Lumumba afgezet omdat deze er niet in slaagde in Kongo orde te herstellen en omdat hij, terecht of ten onrechte, verdacht

${ }^{10}$ Beke, Dirk. "Jef Van Bilsen, de onafhankelijkheid van Congo en de visie op Lumumba." Afrika Focus, nr. 1-2, 2000, pp. 35-60.

${ }^{11}$ Moreels, J.M. "Constitutionele aspecten van de Kongolese krisis". Tijdschrift voor Bestuurswetenschappen en Publiek Recht. 1960, pp. 329-336.

${ }^{12}$ Ook het taalgebruik van J.M. Moreels is hier veelzeggend; we citeren hier de twee meest in het oog springende uitdrukkingen: "Om u de specifieke bantoe-kleur van de Kongolese Kamer weer te geven ..." en "...een typisch staaltje van de wispelturigheid der Bantoe's." Moreels, 1960, p. 332.

${ }^{13}$ Blommaert wijst er aan de hand van de analyse van de brieven tussen Lumumba en VN-topman Hammarskjoeld op dat niet culturele verschillen in visie op democratie en leiderschap de oorzaak zijn van de crisis maar wel de machtsverhoudingen. Blommaert schrijft in zijn besluit: “...that culture is a very relevant concept for the superior party in an interaction, while it is not available as an argument for the inferior one." Afrika Focus, 6, nr. 2, 1990, p. 98 en p.109.

${ }^{14}$ Moreels, 1960, p. 330. 
werd in Kongo met behulp van de Soviet-Unie een, al dan niet communistische dictatuur te willen vestigen." 15

\section{Terug naar het Belgisch grondwettelijk recht van 1831?}

In 1962 behandelt ook Charles Debbasch - nu een van de meest bekende Franse grondwetspecialisten en tevens Afrika-deskundige - de problematiek van de grondwettigheid van de afzetting van Lumumba. ${ }^{16}$ Debbasch wijst erop dat de afzettingsbepaling niet in de resoluties van de Ronde Tafelconferentie voorkomt maar nadien in navolging met de Belgische grondwet in de Fundamentele Wet opgenomen is. Volgens Debbasch heeft die Belgische bepaling slechts zin wanneer we ze in de context plaatsen van de periode wanneer ze is aangenomen (1831). De afzettingsbepaling is in de Belgische geschiedenis nooit toegepast, wel was er soms druk van de Koning op ministers om zelf ontslag te nemen. ${ }^{17}$ In België heeft de grondwettelijke gewoonte deze oude beschikkingen aangepast aan de kenmerken van de parlementaire monarchie. In Congo is de oude bepaling evenwel letterlijk geïnterpreteerd. ${ }^{18}$

Ook de Congo-kenner Crawford Young wijst erop dat de afzetting in contradictie was met de Belgische grondwettelijke praktijk. Hij staaft dit in zijn boek met wat professor Perin hem in een interview berichtte, dat in augustus 1960 Koning Boudewijn geen vertrouwen meer had in de regering van Gaston Eyskens maar dat Eyskens, verontwaardigd, weigerde ontslag te nemen en hij Koning Boudewijn uitdaagde hem te ontslaan op grond van artikel 65. Koning Boudewijn liet daarop zijn verzoek vallen, duidelijk om de 'koningskwestie' niet opnieuw te openen. ${ }^{19}$ Young vervolgt evenwel dat er niets in de Fundamentele Wet stond dat de Belgische gewoonte ook Congo zou binden. Hij stelt dat de rol van een door het parlement verkozen Congolees Staatshoofd niet kan vergeleken worden met die van een erfelijke monarch. ${ }^{20}$

\footnotetext{
${ }^{15}$ Moreels, 1960, p. 330.

${ }^{16}$ Debbasch, Charles. Le problème constitutionnel congolais. Revue du Droit Public en France et à l'étranger, 1962, pp. 25-45.

${ }^{17}$ Debbasch verwijst hiervoor onder meer naar de Belgische hoogleraar: Mast, A. Les Pays du Benelux, L.G.D.J., Paris, 1960, p. 96.

${ }_{18}^{18}$ Debbasch, 1960, pp. 42-43.

19 Young, Crawford. Politics in the Congo. Decolonization and Independence. Princeton, Princeton University Press, 1965, p. 326.

${ }^{20}$ Young, 1965, p. 327.
} 


\section{De afzettingsprocedure in het kader van een moderne parlementaire democratie}

De Fundamentele Wet beoogde op de eerste plaats voor de jonge Congolese republiek de uitbouw van een parlementaire democratie te waarborgen. Ook de regels voor de interpretatie van de grondwettekst werden duidelijk in die zin vastgelegd. Het is merkwaardig dat slechts enkele weken na de publicatie van de Fundamentele Wet totaal anders gerichte interpretaties de bovenhand haalden.

De stelling dat "het ontslag van Lumumba volkomen wettelijk was op grond van de "loi fondamentale", zoals ook Van Bilsen beweert, houdt onvoldoende rekening met de grondwettelijke gewoonte in een parlementaire democratie.

Strikt formeel was door de medeondertekening van het ontslag door minstens één minister, in dit geval trouwens door twee, ${ }^{21}$ voldaan aan een voorwaarde, maar aan slechts één. Deze grondwettelijke procedure hangt in een parlementair stelsel immers altijd samen met een vrijwillig ontslag van de eerste minister of met het feit dat het duidelijk is dat de eerste minister geen meerderheid meer heeft in het parlement. Rechtstreeks in verband hiermee moet verwezen worden naar de memorie van toelichting van de Fundamentele Wet. In deze memorie wordt gesteld dat de interpretatie van artikel 17 (medeondertekening van een minister) dezelfde interpretatie moet krijgen als art. 29 van de Belgische Grondwet. ${ }^{22}$ Daarnaast vermeldt het verslag van de kamercommissie: "De functie van het staatshoofd is in hoofdzaak dezelfde als in België". ${ }^{23}$

Zoals reeds beschreven in voorafgaande bijdrage, vond Van Bilsen vanuit politiek oogpunt de afzetting van Lumumba niet verantwoord en verwijst hij ook naar de belangrijke rol van het parlement. Het ontslag door president Kasavubu van premier Lumumba was niet alleen politiek onverantwoord maar was ook vanuit juridisch oogpunt duidelijk ongrondwettig. Niets in de Fundamentele Wet duidt erop dat het Staatshoofd, zelf al is hij verkozen, het gegeven parlementaire vertrouwen aan de regering kan negeren. ${ }^{24}$

\footnotetext{
${ }^{21}$ Ordonnance du 5 septembre 1960 révoquant le Premier Ministre et certains ministres. Moniteur Congolais, $\mathrm{n}^{\circ}$ 40, 3 octobre 1960.

${ }^{22}$ Parlementaire bescheiden - nr. 489 (1959-1960)

- Memorie van toelichting, nr.1.p. 9.

${ }^{23}$ Verslag van de Commissie, nr. 3, p. 3.

${ }^{24}$ De regering Lumumba had in de nacht van 23 op 24 juni 1960 onweerlegbaar het vertrouwen van de vereiste meerderheid in het parlement verkregen. Dit wordt
} 
Het is begrijpelijk dat Lumumba als rechtstreeks betrokkene naar argumenten zoekt in het grondwettelijk bestel om zijn positie te handhaven. Zijn argumentatie hierbij is vaak erg demagogisch gekleurd, maar dit wil niet zeggen dat het geen waardevolle grondwettelijke interpretaties zou bevatten. Lumumba's eerste reactie is dat Kasavubu hem niet kan ontslaan omdat Kasavubu niet rechtstreeks door het volk is verkozen (maar - zoals reeds aangehaald - door het parlement) terwijl hijzelf rechtstreeks door het volk is verkozen. Deze redenering sluit aan bij het ontworpen constitutioneel model dat gebaseerd is op een parlementair stelsel en niet op een presidentieel stelsel.

Lumumba brengt nog een ander argument naar voor. In zijn verdediging voor de Kamer wijst hij er op dat de medeondertekening gebeurde door twee ministers die voor dergelijke materie geen bevoegdheid hadden (Delvaux was minister-resident in België en had bovendien na het verbreken van de diplomatieke betrekkingen geen welomschreven bevoegdheid en Bomboko was minister van buitenlandse zaken). ${ }^{25}$ In ieder geval moeten we vaststellen dat de medeondertekeningen toch een uitermate formalistisch alibi zijn geworden en daarbij ook in schril contrast staan met de in België geldende grondwettelijke praktijk.

Bovendien kan verwezen worden naar het reeds geciteerde artikel 36 van de Fundamentele Wet waaruit blijkt dat voor de uitoefening van de reglementaire bevoegdheid en voor de uitvoering van wetten door de president, de ontwerpen worden voorgelegd door de eerste minister aan de president. Er kan geïnterpreteerd worden dat het benoemen en ontslaan van de eerste minister strikt genomen niet tot een 'reglementaire' materie behoort ${ }^{26}$ maar de bepalingen van art. 36 tonen aan dat in het Congolees grondwettelijk stelsel er minstens een gezamenlijk optreden van president èn eerste minister moet zijn bij fundamentele beslissingen, zoals ontslag van een minister, inclusief dat van de eerste minister zelf. ${ }^{27}$

trouwens door voorlopig Secretaris-generaal van de Kamer, J.P.Moreels volmondig bevestigd. Zie: Moreels, 1960, p. 336.

25 "Les séances parlementaires du 7 septembre", in Congo 1960. Tome II (édité par J. Gérard-Libois et B. Verhaegen), Bruxelles, CRISP, p. 840.

${ }^{26}$ De Nederlandse tekst van art. 36 van de Fundamentele Wet is wat onduidelijk omdat deze spreekt van 'verordenende bevoegdheid', wat meer zou kunnen zijn dan reglementaire bevoegdheid; in de Franse tekst staat evenwel duidelijk 'pouvoir réglementaire'.

${ }^{27}$ Merk op dat bijvoorbeeld zelfs in de Franse grondwet van 1958 (van de Gaulle) uitdrukkelijk bepaald is dat het ontslag van de eerste minister (en van ministers) door de president moet gebeuren op voorstel van de eerste minister (art.8). Dit grondwettelijk stelsel kan nochtans als semi-presidentieel geklasseerd worden; zo zien we onder meer dat de president de ministerraad voorzit (art. 9). 


\section{De betwistbare interpretatie dat de afzetting van Lumumba grondwettig zou geweest zijn, is een wezenlijk element in de machtstrijd geworden}

Uiteraard kan over de verdere legitimiteit en grondwettigheid van het nadien door Lumumba samengeroepen parlement gediscuteerd worden, ${ }^{28}$ maar bij de afzetting is door Kasavubu ongrondwettig geanticipeerd op een eventuele parlementaire motie van wantrouwen of op een eventueel ongrondwettig parlement.

De grondwettelijke bescherming van de eerste minister en de regering zijn juist de waarborgen die dit anticiperen moeten verhinderen omdat dergelijke voortijdige beslissingen onomkeerbare politieke gevolgen kunnen hebben. Dit laatste heeft het dramatisch vervolg van de politieke geschiedenis van Congo duidelijk aangetoond.

Door te aanvaarden dat de afzetting van Lumumba 'grondwettig' was werd Lumumba buiten het grondwettelijk bestel geduwd en konden alle verdere politieke daden uitgaande van Lumumba door zijn tegenstrevers en vijanden als illegaal worden bestempeld.

${ }^{28}$ Onmiddellijk na de 'afzetting' behoudt de regering Lumumba een relatieve meerderheid in het parlement. We zien dat de Kamer (op 7 september met 60 tegen 20 op 137 leden) en de Senaat (op 8 september met 42 tegen 2 en 6 onthoudingen op 84 leden) zowel de afzetting van Lumumba door Kasavubu als deze van Kasavubu door Lumumba 'herroepen'. Young, 1965, p. 328. Merk op dat voor een motie van wantrouwen een wachtperiode van achtenveertig uur vereist was en vervolgens ofwel twee derden van de stemmen van de aanwezige leden van beide kamers, ofwel in elke van beide kamers de volstrekte meerderheid van alle leden ervan. (Fundamentele Wet, art. 43). 